\title{
Tissue Bioengineer: Mix and Match
}

\author{
Felipe A Soria*, Josue Delgado and Luciano Alves \\ SIMNSA Medyca, Mexico
}

*Corresponding author: Felipe A Soria, Department of Refractiv Surgery, University of Montemorelos, Ave Paseo Tijuana No.406 Zona Urbana Rio, Mexico, PC.22010, Mexico, Tel: +52 664-370-9566; Email: soriafelipe.md@gmail.com

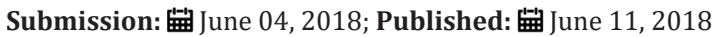

\section{Opinion}

Through the very first publication [1] on tissue bioengineer in the year 1966, the questions have arised between a heterologous, autologous or now days, printed tissue. Every mature cell, involving from the cell membrane, passing through the organellas and reaching the DNA has a specific function in the human body. Why not share and transform cells from different organs that have the same function but probably nos the same morphology?

Mesothelial cells form a monolayer of specialized pavementlike cells that line the body's serous cavities and internal organs. The primary function of this layer, termed the mesothelium, is to provide a slippery, non-adhesive and protective surface. However, mesothelial cells play other pivotal roles involving transport of fluid and cells across the serosal cavities, antigen presentation, inflammation and tissue repair, coagulation and fibrinolysis and tumour cell adhesion. With this concept and the knowledge of endothelium corneal cells is that the question arised if any similarity where between them, not only theoretically [2].

The purpose of the study [3] we did was to evaluate whether mouse adipose tissue mesothelial cells (ATMCs) shared morphologic and biochemical characteristics with mouse corneal endothelial cells (CECs) and to evaluate their capacity to adhere to the decellularized basal membrane of human anterior lens capsules (HALCs) as a potential tissue-engineered surrogate for corneal endothelium replacement.

The results were surprising, corneal endothelial cells and ATMCs share morphologic (structural) and marker (functional) similarities [corrected]. The ATMCs adhered and formed structures mimicking focal adhesion complexes with the HALC basal membrane. Monolayer structure and achieved density of ATMCs support the proposal to use adult human mesothelial cells (MCs) as a possible surrogate for damaged corneal endothelium. Mixing and matching is a possibility to have functional cells to be transfered from one healthy tissue to another pathological tissue.
Latest studies published in tissue engineer has a broad spectrum. New study on future autologous pancreatic cells have shown the development tissue-engineered human pancreatic islets in a laboratory that develop a circulatory system, secrete hormones like insulin and successfully treat sudden-onset type 1 diabetes in transplanted mice [4].

On the other hand, robots are playing a main role in developing stem cells. A robotic system has been developed to automate the production of human mini-organs derived from stem cells. The ability to rapidly, mass produce or ganoids promises to expand the use of mini-organs in basic research and drug discovery. The system was tested in producing kidney or ganoids [5].

Up to date, we need to continue finding new alternatives for autologous cell transplants meanwhile study on stem cells development is the leading field for future tissue replacement in every area, despite that the uncertainity in science is a certainity.

\section{References}

1. Ridge MD, Wright V (1966) The directional effects of skin. A bioengineering study of skin with particular reference to Langer's lines. J Invest Dermatol 46(4): 341-346.

2. Mutsaers SE (2004) The mesothelial cell. Int J Biochem Cell Biol 36(1): $9-16$.

3. Lachaud CC, Soria F, Escacena N, Quesada-Hernández E, Hmadcha A, et al. (2014) Mesothelial cells: a cellular surrogate for tissue engineering of corneal endothelium. Invest Ophthalmol Vis Sci 55(9): 5967-5978.

4. Yoshinobu T, Keisuke S, Tatsuya K, Takanori T, Hideki T (2018) Selfcondensation culture enables Vascularization of tissue fragments for efficient therapeutic transplantation. Cell Reports 23(6): 1620-1629.

5. Stefan MC, Nelly MC, Jennifer LH, Rajasree M, James A, et al. (2018) Highthroughput screening enhances kidney organoid differentiation from human pluripotent stem cells and enables automated multidimensional phenotyping. Cell Stem Cell 22(6): 929-940. 
Creative Commons Attribution 4.0 International License

For possible submissions Click Here

\begin{tabular}{|l} 
RMES $\begin{array}{c}\text { Research in } \\
\text { Medical } 8 \\
\text { Engineering } \\
\text { sciences }\end{array}$ \\
Benefits of Publishing with us \\
B High-level peer review and editorial services
\end{tabular}

